\title{
von Willebrand Protein Facilitates Platelet Incorporation in Polymerizing Fibrin
}

\author{
Joseph Loscalzo, * Aida Inbal, $¥$ and Robert I. Handin \\ Division of Vascular Medicine and Cardiology Division, ${ }^{*}$ and Hemostasis Unit and Hematology Division, $\ddagger$ Department of Medicine, \\ Brigham and Women's Hospital and Harvard Medical School, Boston, Massachusetts 02115
}

\begin{abstract}
von Willebrand protein was found to promote the incorporation of platelets into evolving fibrin thrombi. Using formalin-treated or fresh platelets, both the initial rate and extent of platelet incorporation into polymerizing fibrin were dependent on von Willebrand protein. von Willebrand protein was incorporated into evolving fibrin thrombi in parallel with platelets. Soluble fibrin monomer covalently linked to acrylonitrile beads (Matrex 102) bound von Willebrand protein specifically and saturably with an apparent approximate dissociation constant $\left(K_{D}\right)$ of 15 $\mu \mathrm{g} / \mathrm{ml}$. Glycocalicin, the water-soluble proteolytic fragment of glycoprotein Ib, bound to fibrin monomer in this system specifically and saturably, as well, with an apparent approximate $K_{D}$ of $5 \mu \mathrm{g} / \mathrm{ml}$, but only in the presence of saturating concentrations of von Willebrand protein. These data demonstrate that $(a)$ the initial rate and extent of platelet incorporation into evolving fibrin thrombi are dependent on von Willebrand protein; (b) von Willebrand protein serves as a link between polymerizing fibrin and platelet surface glycoprotein Ib; and (c) von Willebrand protein binds to fibrin monomer and is thereby able to bind to platelet surface glycoprotein Ib in the absence of ristocetin.
\end{abstract}

\section{Introduction}

In circulating blood, platelets are continuously exposed to von Willebrand protein (vWF) ${ }^{1}$ and fibrinogen, but only bind these proteins during the formation of hemostatic plugs at sites of vascular injury. vWF is a polymeric plasma glycoprotein that plays a central role in the events of primary hemostasis. Binding both to collagen (1-8) and to the platelet surface (9-14), it links the platelet with the subendothelium at sites of vascular injury (15-17). Although incubation of platelets in vitro with polycations, such as the antibiotic, ristocetin, promotes vWF binding to glycoprotein $\mathrm{Ib}$, the physiologic regulator of this binding has not been elucidated. In contrast, it has been clearly shown that exposure of platelets to ADP and to a product of the coagulation cascade, thrombin, promotes the binding of fibrinogen and vWF to glycoprotein IIb/IIIa $(13,14,18)$. Because the events of pri-

\footnotetext{
Address reprint requests to Dr. Loscalzo.

Received for publication 30 April 1985 and in revised form 10 June 1986.
}

1. Abbreviations used in this paper: FM-Matrex, fibrin monomer-immobilized Matrex beads; FP, formalin-fixed platelets; GPRP, glycyl-Lprolyl-L-arginyl-L-proline; $K_{\mathrm{D}}$, dissociation constant; PPACK, D-phenylalanyl-L-prolyl-L-arginine chloromethylketone $\cdot 2 \mathrm{HCl}$; SFM, soluble fibrin monomer; TBS, Tris-buffered saline; vWF, von Willebrand factor.

J. Clin. Invest.

(c) The American Society for Clinical Investigation, Inc.

0021-9738/86/10/1112/06 \$1.00

Volume 78, October 1986, 1112-1119 mary and secondary hemostasis are temporally related and physically coupled, it is likely that one of the intermediates generated during coagulation stimulates vWF binding to glycoprotein Ib, as well.

In addition to the bifunctional role of fibrinogen as a platelet adhesive protein and a thrombin substrate, there are several other examples of interactions between platelets and coagulation proteins of importance. Platelets bind Factors $\mathrm{Va}$ and $\mathrm{Xa}$ and provide a surface that accelerates prothrombin conversion (19-21). Thrombin not only converts fibrinogen to fibrin, but also induces platelet activation and secretion. Platelets are also a source of Factor V (22), fibrinogen (23), and VWF $(24,25)$, the latter protein being important not only for platelet adhesion, but also as a carrier for Factor VIII $_{c}$. Even in the process of clot dissolution, plasmin proteolyzes both fibrin and glycoprotein Ib, a vWF receptor, from the platelet surface (26), thereby facilitating fibrin and platelet removal from the thrombus.

These interactions between platelets and coagulation proteins depend critically on their physical proximity. Platelets are readily incorporated into the fibrin thrombus (27) itself, and this incorporation has been shown to depend on their interaction with polymerizing fibrin (28). In addition, fibrin polymers formed in the presence of platelets are larger than those formed in their absence (28) and patients with vWF deficiency produce thrombi of smaller volume than normal (29).

It thus appears that the interaction of platelets with polymerizing fibrin is an important hemostatic event that serves to poise the events of primary and secondary hemostasis in optimal relationship to one another. In this paper, we show that vWF is the adhesive protein that mediates this platelet-fibrin interaction and that it does so by binding to fibrin monomer and to platelet surface glycoprotein Ib. This observation provides a new and important example of coupling between primary and secondary hemostatic processes and offers a possible mechanism for the selective activation of platelet vWF receptors during hemostasis. We propose that this vWF-fibrin-platelet interaction augments flow-dependent platelet adhesion following vascular injury.

\section{Methods}

Materials. Plasmin and purified human fibrinogen were purchased from Kabi Vitrum, Stockholm, Sweden. Plasminogen-free bovine thrombin was obtained from Miles Pharmaceuticals, Naperville, IL. Bothrops atrox venom, aprotinin, and glycyl-L-prolyl-L-arginyl-L-proline (GPRP) were purchased from Sigma Chemical Co., St. Louis, MO. Ristocetin and vWF-deficient plasma were purchased from Bio-Data Corporation, Horsham, PA. Rabbit polyclonal anti-vWF antibody was purchased from Accurate Chemicals, Westbury, NY. D-Phenylalanyl-L-prolyl-L-arginine chloromethylketone $2 \mathrm{HCl}$ (PPACK) was obtained from CalbiochemBehring Corp., La Jolla, CA. Iodo-beads were purchased from Pierce Chemical Co., Rockford, IL. ${ }^{125} \mathrm{I}-\mathrm{Na}$ was obtained from Amersham Corp., Arlington Heights, IL. Matrex Pel 102 bead were purchased from Amicon Corp., Danvers, MA. Murine monoclonal anti-glycoprotein Ib (6D1) and anti-glycoprotein IIb/IIIa (10E5) were the generous gifts of Dr. Barry Coller, State University of New York at Stony Brook, NY. For some 
experiments pure human fibrinogen free of detectable fibronectin and vWF was kindly provided by Dr. Jacek Hawiger, New England Deaconess Hospital, Boston, MA. Sephacryl S-1000 was obtained from Pharmacia Fine Chemicals, Stockholm, Sweden.

Platelets. Venous blood was obtained from volunteers who had not ingested acetylsalicylic acid for at least $10 \mathrm{~d}$ and was anticoagulated with $13 \mathrm{mM}$ sodium citrate. Platelet-rich plasma (PRP) was prepared by centrifugation at $160 \mathrm{~g}$ for $10 \mathrm{~min}$. Platelet counts were determined with a Coulter counter (model F, Coulter Electronics, Inc., Hialeah, FL). Platelets were fixed with formalin (FP) according to published methods $(30,31)$ and stored at $4^{\circ} \mathrm{C}$ for up to $2 \mathrm{wk}$ with no appreciable loss of agglutinability to $\mathrm{vWF}$ and ristocetin.

Platelet aggregation. Platelet aggregation was monitored using a standard nephelometric technique (32) in which $0.4-\mathrm{ml}$ aliquots of platelet suspensions were incubated at $37^{\circ} \mathrm{C}$ and stirred at $900 \mathrm{rpm}$ in a dualchannel aggregometer (Payton Associates, Inc., Buffalo, NY). Aggregation or agglutination was induced by addition of agonist and changes in light transmittance recorded using an XY-recorder (Omniscribe, Houston Instruments, Austin, TX).

$\checkmark W F$ preparation. $v W F$ was prepared from a cryoprecipitate of human plasma as described previously (33). vWF activity was determined by the ristocetin assay $(34,35)$ using FP. Only the earliest eluting fractions from the Sephacryl S-1000 column of vWF were used in the experiments presented here to minimize fibrinogen and fibronectin contamination. These fractions contained the largest multimers of vWF (with molecular weights between 5 and $10 \times 10^{6} \mathrm{D}$ and larger material that could not be resolved by the standard electrophoretic method of Ruggeri and Zimmerman $(36,37)$; the size of these multimers was further analyzed by electron microscopy and quasielastic light scattering $(38,39)$ and found to range in contour length from 100 to $1,300 \mathrm{~nm}$ ) and were found to have $<0.2 \mu \mathrm{g}$ of fibrinogen per $100 \mu \mathrm{g}$ of $\mathrm{vWF}$ and $<1.5 \mu \mathrm{g}$ of fibronectin per $100 \mu \mathrm{g}$ of vWF, as determined in solid-phase immunoassays using immunoadsorbed polyclonal rabbit anti-human fibronogen and fibronectin antisera (Calbiochem-Behring Co.), respectively.

Glycocalicin preparation. Glycocalicin, the water-soluble fragment of platelet membrane glycoprotein Ib, was prepared as described previously (40).

Platelet radioiodination. Both fresh and formalin-treated platelets were radioiodinated with ${ }^{125} \mathrm{I}-\mathrm{Na}$ by the lactoperoxidase method $(41$, 42). Fresh platelets had a specific activity of $1.5 \times 10^{7} \mathrm{cpm} / 10^{9}$ platelets, while ${ }^{125}$ I-labeled FP had a specific activity of $2.6 \times 10^{7} \mathrm{cpm} / 10^{9} \mathrm{FP}$. Both ${ }^{125} \mathrm{I}$-platelets and ${ }^{125} \mathrm{I}$-FP agglutinated normally on addition of 1.0 $\mathrm{mg} / \mathrm{ml}$ ristocetin in the presence of as little as $8 \mu \mathrm{g} / \mathrm{ml}$ of purified vWF.

Protein radioiodination. vWF and highly purified fibrinogen were both iodinated using Iodo-beads. One Iodo-bead was incubated with $0.5-1.0 \mathrm{mCi}$ of ${ }^{125} \mathrm{I}-\mathrm{Na}$ (for vWF, glycocalicin, and fibrinogen) or of ${ }^{131} \mathrm{I}$ $\mathrm{Na}$ (for vWF) at $25^{\circ}$ for $15-20 \mathrm{~min}$. To this was added $1.0 \mathrm{ml}$ of 0.1 $\mathrm{mg} / \mathrm{ml}$ protein in $10 \mathrm{mM}$ Tris, $\mathrm{pH} 7.8,0.15 \mathrm{M} \mathrm{NaCl}$ (TBS) and the incubation continued for 20-25 min with gentle rocking. The protein solution was then applied to a $10 \times 0.7 \mathrm{~cm}$ Sephadex G-25 column that had been equilibrated with $1 \mathrm{ml}$ of $5 \mathrm{mg} / \mathrm{ml}$ bovine serum albumin in TBS. Twelve $0.3-\mathrm{ml}$ fractions were collected and assayed for total and $25 \%$ trichloroacetic acid-precipitable radioactivity. Routinely, column fractions five through eight contained maximal protein-bound counts with an $\sim 0.1-0.2 \mu \mathrm{Ci} / \mu \mathrm{g} \mathrm{sp}$ act. These fractions were either used immediately or stored at $4^{\circ} \mathrm{C}$ for up to 1 wk without appreciable loss of protein-bound counts.

Soluble fibrin monomer preparation. Soluble fibrin monomer (SFM) was prepared by adding bovine thrombin at a final concentration of 2 $3 \mathrm{U} / \mathrm{ml}$ to a $2-\mathrm{mg} / \mathrm{ml}$ solution of highly purified human fibrinogen in TBS with $2.5 \mathrm{mM}$ GPRP added to inhibit polymerization (43). After incubation for $20 \mathrm{~min}$ at room temperature PPACK, a specific inhibitor of thrombin's amidolytic activity (44), was added to a final concentration of $48 \mu \mathrm{M}$. Under these conditions, no appreciable fibrin polymer was detectable, either by gross inspection or by turbidity change at $350 \mathrm{~nm}$ (45), for up to $1.5 \mathrm{~h}$ at room temperature. In the absence of GPRP, 95\% of fibrinogen was clottable.

Assay of platelet and protein incorporation in fibrin clot. Suspensions of platelets (fresh platelets, FP, or radioiodinated fresh platelets or FP) at a total final concentration of $3-5 \times 10^{4} / \mu 1$ in TBS were placed in 1ml cylindrical glass cuvettes containing a $1.5 \times 9 \mathrm{~mm}$ cylindrical stirring bar. Plasma, purified vWF, ${ }^{131} \mathrm{I}$-vWF, purified fibrinogen, ${ }^{125} \mathrm{I}$-fibrinogen, or SFM were added, the volume was brought to $0.9 \mathrm{ml}$ with TBS, and the suspension stirred at $900 \mathrm{rpm}$ at $25^{\circ} \mathrm{C}$. Bovine thrombin or Bothrops atrox venom was then added and $25-\mu \mathrm{l}$ aliquots of the suspension were removed from the periphery of the solution away from the central vortex and evolving clot to determine residual, unincorporated radioactivity or, in some experiments, to perform directly platelet counts. The fibrin clot formed on the stirring bar and often extended to the meniscus of the solution through the center of the cuvette, but did not touch the sides of the cuvette where the samples were withdrawn.

In most cases, the fraction of total platelets incorporated in evolving thrombus was determined, either by measuring residual, unincorporated platelets or by determining radioactivity incorporated directly in the clot after washing the clot three times with TBS. Using both techniques, 98\% of all radioactivity (free and incorporated in thrombus) was routinely recovered to within $2 \%$. In a typical experiment using $5 \times 10^{4} \mathrm{FP} / \mu \mathrm{l}$, a 1:10 dilution of normal plasma, and $2 \mathrm{U} / \mathrm{ml}$ bovine thrombin, $49 \pm 5 \%$ of platelets were incorporated after $20 \mathrm{~min}$ at $25^{\circ} \mathrm{C}$. Using ${ }^{131} \mathrm{I}$-vWF at a total vWF concentration of $17 \mu \mathrm{g} / \mathrm{ml}$ or ${ }^{125} \mathrm{I}$-fibrinogen at $280 \mu \mathrm{g} / \mathrm{ml}$ under the same conditions, $13 \pm 1 \%$ or $40 \pm 5 \%$ of the added radioactivity was incorporated, respectively, by $20 \mathrm{~min}$ at $25^{\circ} \mathrm{C}$. In early experiments, $10 \mathrm{mM}$ EDTA was used to prevent Factor XIII from potentially covalently cross-linking fibrin polymer to vWF; the elimination of EDTA from later experiments did not significantly influence the effect of vWF on the initial rate or extent of platelet incorporation. Under the conditions of this assay, $9.1 \pm 0.3 \times 10^{4}$ fresh platelets or FP were routinely incorporated per microgram of fibrin.

Binding of SFM to $v W F$. A $6.0 \times 0.7 \mathrm{~cm}$ Sephacryl S-1000 column was used to separate fibrinogen and SFM from vWF and to assess the binding of SFM to vWF. In 50- $\mu$ l sample volumes, $70 \mu \mathrm{g}$ of ${ }^{125}$ I-fibrinogen $\left(1.5 \times 10^{6} \mathrm{cpm}\right), 70 \mu \mathrm{g}$ of ${ }^{125} \mathrm{I}-\mathrm{SFM}\left(1.5 \times 10^{6} \mathrm{cpm}\right)$, or $50 \mu \mathrm{g}$ of $\mathrm{vWF}$ with ${ }^{125}$ I-fibrinogen or ${ }^{125} \mathrm{I}$-SFM were applied and the column eluted with TBS, $2 \mathrm{mM}$ GPRP, and $48 \mu \mathrm{M}$ PPACK at $25^{\circ} \mathrm{C}$. The radioactivity in each of twenty $200-\mu \mathrm{l}$ fractions was measured and the results plotted as a function of fraction number. The void volume was determined using the earliest eluting fractions of vWF (i.e., the largest multimers) obtained from a preparative Sephacryl S-1000 column (33) and found to be $1.4 \mathrm{ml}$.

Binding of glycocalicin to $\mathrm{vWF}$ in the presence of SFM. A $6.0 \times 0.7$ $\mathrm{cm}$ Sephacryl S-1000 column was also used to separate glycocalicin from vWF and SFM and to assess the binding of glycocalicin to vWF, SFM, or both vWF and SFM. In 50- $\mu$ l sample volumes, $30 \mu \mathrm{g}$ of ${ }^{125} \mathrm{I}$-glycocalicin $\left(1.5 \times 10^{6} \mathrm{cpm}\right)$ were applied alone, with $50 \mu \mathrm{g}$ of $\mathrm{vWF}$, with $70 \mu \mathrm{g}$ of SFM, or with $50 \mu \mathrm{g}$ of vWF and $70 \mu \mathrm{g}$ of SFM and the column eluted with TBS, $2 \mathrm{mM}$ GPRP, and $48 \mu \mathrm{M}$ PPACK at $25^{\circ} \mathrm{C}$. The radioactivity in each of twenty $200-\mu \mathrm{l}$ fractions was measured and the results plotted as a function of fraction number. The void volume was determined as described above.

Preparation of fibrin monomer-immobilized Matrex beads. Fibrinogen was covalently coupled to solid beads of polymerized acrylonitrile with free carboxyl and $N$-hydroxysuccinimide carboxylate ester groups on their surface (Matrex 102) essentially according to the method of Coller (46). Using ${ }^{125}$ I-fibrinogen, $\sim 4.1 \times 10^{5}$ molecules of fibrinogen bound per 3- $\mu \mathrm{m}$ diameter bead with a $95 \%$ coupling efficiency. Fibrinogen covalently coupled to the beads was then converted to fibrin monomer by incubation with $4 \mathrm{U} / \mathrm{ml}$ of bovine thrombin for $1 \mathrm{~h}$ at $25^{\circ} \mathrm{C}$. At the end of the incubation, PPACK was added to $48 \mu \mathrm{M}$ and the bead washed three times with TBS. Because of the steric constraints of coupling, fibrin monomer was unable to assemble into polymer on the bead surface and this fibrin monomer-immobilized Matrex (FM-Matrex) was used in the binding experiments described below.

Binding of $v W F$ to FM-Matrex. To quantitate better the interaction between vWF and fibrin monomer demonstrated chromatographically, direct binding of ${ }^{125} \mathrm{I}-\mathrm{vWF}$ to FM-Matrex was studied. Increasing concentrations of vWF ( 1 to $25 \mu \mathrm{g} / \mathrm{ml}$ ) were incubated with $3.2 \times 10^{6} \mathrm{FM}$ - 
Matrex beads (on the surface of which was $4.1 \times 10^{5}$ fibrin monomers/ bead) in a 0.4-ml total volume in TBS for $1 \mathrm{~h}$ with stirring at $900 \mathrm{rpm}$ at $25^{\circ} \mathrm{C}$. At the end of the incubation period, $0.1 \mathrm{ml}$ of the incubation suspension was layered over $0.2 \mathrm{ml}$ of $20 \%$ sucrose in TBS and centrifuged at $8,700 \mathrm{~g}$ for $2.5 \mathrm{~min}$. The tip of the centrifuge tube was excised and radioactivity counted in order to measure binding. Nonspecific binding was determined by adding a 20-fold excess of unlabeled vWF and accounted for $\sim 27 \%$ of the total bound counts in this system. It is important to note that ${ }^{125} \mathrm{I}-\mathrm{vWF}$ bound to control, fibrinogen-immobilized or bovine serum albumin-immobilized Matrex beads nonspecifically, that is, linearly throughout the concentration range tested without achieving saturation and without displacement by a 20 -fold excess of unlabeled yWF.

Binding of glycocalicin to FM-Matrex and $v W F$. Similar experiments were performed using ${ }^{125} \mathrm{I}$-glycocalicin and FM-Matrex in the presence of (saturating) concentrations of $\mathrm{vWF}(20 \mu \mathrm{g} / \mathrm{ml})$. Increasing concentrations of glycocalicin $(0.85$ to $17 \mu \mathrm{g} / \mathrm{ml})$ were incubated with $2.4 \times 10^{6}$ FM-Matrex beads in 0.3-ml total volume in TBS for $1 \mathrm{~h}$ with stirring at $900 \mathrm{rpm}$ at $25^{\circ} \mathrm{C}$. At the end of the incubation period, $0.1 \mathrm{ml}$ of the incubation suspension was layered over $0.2 \mathrm{ml}$ of $20 \%$ sucrose in TBS and centrifuged at $8,700 \mathrm{~g}$ for $2.5 \mathrm{~min}$. The tip of the centrifuge tube was excised and radioactivity counted in order to measure binding. Nonspecific binding was determined by adding a 20 -fold excess of unlabeled glycocalicin and accounted for $\sim 76 \%$ of the total bound counts in this system. Using control fibrinogen-immobilized or bovine serum albuminimmobilized Matrex beads, ${ }^{125} \mathrm{I}$-glycocalicin bound nonspecifically only, that is, linearly over the concentration range tested without achieving saturation and without displacement by a 20 -fold excess of unlabeled glycocalicin.

Protein determinations. Protein concentrations were determined by the method of Lowry and colleagues (47).

\section{Results}

Dependence of platelet incorporation in evolving fibrin thrombus on $v W F$. As shown in Table I, there is a direct relationship between the quantity of vWF present in plasma and the interaction of FP with polymerizing fibrin. When normal platelet-poor plasma was used as a source of vWF, $52 \pm 2 \%$ of total platelets were incorporated by $20 \mathrm{~min}$. Using vWF-deficient plasma with no ristocetin cofactor activity, only $30 \pm 4 \%$ of total platelets were incorporated. Adding increasing concentrations of purified vWF, from 5 to $15 \mu \mathrm{g} / \mathrm{ml}$, increased the extent of incorporation of FP to that found with normal plasma.

Effect of $v W F$ on extent and initial rate of platelet incorporation in evolving fibrin clot. Fig. 1 shows the interaction of ${ }^{125} \mathrm{I}$ FP with polymerizing fibrin as a function of time after addition of $2 \mathrm{U} / \mathrm{ml}$ of bovine thrombin to a 1:10 dilution of normal or $v W F$-deficient plasma. Both the rate and extent of incorporation

Table I. Dependence of Platelet Incorporation in Fibrin Thrombi on von Willebrand Protein Concentration

\begin{tabular}{ll}
\hline & $\begin{array}{l}\text { Extent } \\
\text { (Fx of total platelets) }\end{array}$ \\
\hline vWF-deficient plasma & $0.30 \pm 0.04$ \\
vWF-deficient plasma $+5 \mu \mathrm{g} / \mathrm{ml} \mathrm{vWF}$ & $0.38 \pm 0.05$ \\
vWF-deficient plasma $+15 \mu \mathrm{g} / \mathrm{ml}$ vWF & $0.45 \pm 0.05$ \\
vWF-deficient plasma $+30 \mu \mathrm{g} / \mathrm{ml}$ vWF & $0.50 \pm 0.04$ \\
Normal plasma & $0.52 \pm 0.02$
\end{tabular}

Bovine thrombin was added to $2 \mathrm{U} / \mathrm{ml}$ to initiate thrombus formation to suspensions of $5 \times 10^{4} \mathrm{FP} / \mu \mathrm{l}$ in undiluted $\mathrm{vWF}$-deficient and normal plasma. The values represent the results of three experiments done in triplicate and are expressed as the mean \pm SEM.

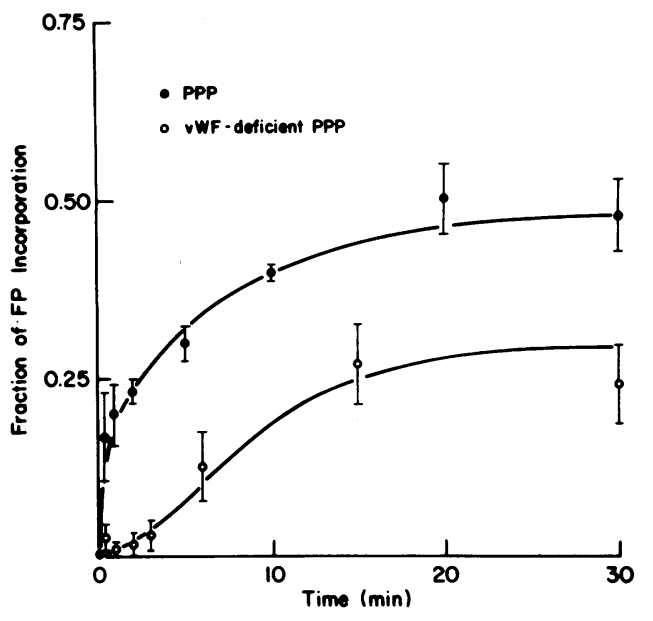

Figure 1. Effect of vWF on time course of FP incorporation into fibrin thrombi. To $0.9 \mathrm{ml}$ of a platelet suspension containing $5 \times 10^{4}{ }^{125} \mathrm{I}$ $\mathrm{FP} / \mu \mathrm{l}$ in $10 \%$ normal plasma or $10 \% \mathrm{vWF}$-deficient plasma was added $2 \mathrm{U} / \mathrm{ml}$ bovine thrombin and the change in unincorporated radioactivity determined at various times of incubation at $25^{\circ} \mathrm{C}$ with stirring at $900 \mathrm{rpm}$. Each point represents the mean \pm SEM of three to five experiments done in duplicate.

of FP were dramatically affected by vWF, its presence increasing the initial rate of incorporation $\sim 30$-fold and the extent of incorporation $\sim 1.7$-fold (Fig. 1 and Table II). Addition of vWF to $18 \mu \mathrm{g} / \mathrm{ml}$ partly restored the initial rate and completely restored the extent of incorporation (Table II).

In order to assess better the molecular determinants of incorporation, the experiments listed in Table II were performed. Plasmin treatment of FP, which selectively removes glycoprotein Ib and eliminates ristocetin-dependent agglutination (26), reduced both the initial rate and extent of FP incorporation in fibrin thrombus. Both a monoclonal anti-glycoprotein Ib antibody and a polyclonal anti-vWF antibody, at concentrations sufficient to completely inhibit ristocetin-dependent agglutination, reduced the initial rate and extent of incorporation of FP in polymerizing fibrin. In contrast, a monoclonal antibody directed against the other major vWF receptor on the platelet surface, glycoprotein IIb/IIIa, did not change the rate or extent of incorporation of vWF.

Similar experiments were performed with fresh platelets, as indicated in the lower half of Table II. Both $2 \mathrm{U} / \mathrm{ml}$ bovine thrombin and $50 \mathrm{ng} / \mathrm{ml}$ Bothrops atrox venom added to a 1:10. dilution of normal plasma led to platelet incorporation in evolving fibrin thrombi. With fresh platelets and thrombin, the initial rate of incorporation was approximately one-fourth that observed with FP, while the extent of incorporation was slightly less than twice that with FP. With fresh platelets and $B$. atrox venom, the initial rate of incorporation was approximately one-eighth that with thrombin and FP, while the extent of incorporation was only slightly greater. Using a 1:10 dilution of $\mathrm{vWF}$-deficient plasma with thrombin or Bothrops atrox venom significantly reduced the rate and extent of fresh platelet incorporation. Again, addition of purified vWF to vWF-deficient plasma completely restored the extent and partly restored the initial rate of incorporation induced by both enzymes.

Simultaneous incorporation of VWF and FP in polymerizing fibrin was assessed by adding both ${ }^{131} \mathrm{I}-\mathrm{vWF}$ and ${ }^{125} \mathrm{I}-\mathrm{FP}$ to the same suspension. Incorporation was determined from $30 \mathrm{~s}$ to 
Table II. Initial Rate and Extent of Platelet Incorporation in Fibrin Thrombi

\begin{tabular}{|c|c|c|}
\hline & Initial rate & Extent \\
\hline & platelets/min & Fx total platelets \\
\hline \multicolumn{3}{|l|}{${ }^{125} \mathrm{I}-\mathrm{FP} *$ (2 U/ml thrombin) } \\
\hline Normal plasma & $9.75 \times 10^{6}$ & $0.49 \pm 0.05$ \\
\hline vWF-deficient plasmał & $0.33 \times 10^{6}$ & $0.29 \pm 0.03$ \\
\hline Plasmin treatment $\S$ & $0.12 \times 10^{6}$ & $0.27 \pm 0.02$ \\
\hline Anti-Gplb antibody" & $0.37 \times 10^{6}$ & $0.32 \pm 0.04$ \\
\hline Anti-vWF antibodyI & $0.30 \times 10^{6}$ & $0.31 \pm 0.04$ \\
\hline Anti-GpIIb/IIIa antibody** & $9.05 \times 10^{6}$ & $0.48 \pm 0.05$ \\
\hline \multicolumn{3}{|l|}{ vWF-deficient plasma } \\
\hline$+18 \mu \mathrm{g} / \mathrm{ml} \mathrm{vWF}$ & $3.30 \times 10^{6}$ & $0.48 \pm 0.05$ \\
\hline \multicolumn{3}{|l|}{$\begin{array}{l}{ }^{125} \mathrm{I} \text {-plateletsł }(2 \mathrm{U} / \mathrm{ml} \\
\text { thrombin) }\end{array}$} \\
\hline Normal plasma & $2.63 \times 10^{6}$ & $0.87 \pm 0.08$ \\
\hline vWF-deficient plasma & $0.16 \times 10^{6}$ & $0.35 \pm 0.04$ \\
\hline \multicolumn{3}{|l|}{ vWF-deficient plasma } \\
\hline$+15 \mu \mathrm{g} / \mathrm{ml} \mathrm{vWF}$ & $1.60 \times 10^{6}$ & $0.74 \pm 0.09$ \\
\hline \multicolumn{3}{|l|}{$\begin{array}{c}{ }^{125} \mathrm{I} \text {-platelets } \$(50 \mathrm{ng} / \mathrm{ml} \\
\text { B. atrox venom) }\end{array}$} \\
\hline Normal plasma & $1.23 \times 10^{6}$ & $0.59 \pm 0.05$ \\
\hline vWF-deficient plasma & $0.075 \times 10^{6}$ & $0.29 \pm 0.02$ \\
\hline \multicolumn{3}{|l|}{ vWF-deficient plasma } \\
\hline$+15 \mu \mathrm{g} / \mathrm{ml} \mathrm{vWF}$ & $1.10 \times 10^{6}$ & $0.51 \pm 0.04$ \\
\hline
\end{tabular}

All results are expressed as the mean \pm SEM of two or three experiments done in triplicate.

$* 5 \times 10^{4} \mathrm{FP} / \mathrm{ul}$ were used in these assays. Bovine thrombin at $2 \mathrm{U} / \mathrm{ml}$ was added to initiate thrombus formation. Plasmas were diluted 1:10 in each experiment.

$\ddagger \mathrm{vWF}$-deficient plasma contained no detectable ristocetin activity and $<5 \%$ vWF antigen.

$\S$ Plasmin treatment of FP was performed as previously described (26). " $2.2 \mu \mathrm{g} / \mathrm{ml}$ of a monoclonal anti-GpIb antibody (6D1) was used.

I $80 \mu \mathrm{g} / \mathrm{ml}$ of a polyclonal anti-vWF antibody was used.

** $4.4 \mu \mathrm{g} / \mathrm{ml}$ of a monoclonal anti-GpIIb/IIIa antibody was used. $\ddagger \ddagger 3 \times 10^{4}$ fresh platelets/ $\mu \mathrm{l}$ were used in these assays. Bovine thrombin at $2 \mathrm{U} / \mathrm{ml}$ was added to initiate thrombus formation.

$\S \S 3 \times 10^{4}$ fresh platelets $/ \mu \mathrm{l}$ were used in these assays. $50 \mathrm{ng} / \mathrm{ml}$ $B$. atrox venom was added to initiate thrombus formation.

$20 \mathrm{~min}$ after addition of $2 \mathrm{U} / \mathrm{ml}$ bovine thrombin. A good correlation was noted between $\mathrm{vWF}$ and FP incorporation ( $r$ $=0.91$ ) over a wide range of concentrations of both species (from 0 to $2,000 \mathrm{ng}$ of vWF and from 0 to $2.2 \times 10^{7} \mathrm{FP}$ incorporated per $0.9-\mathrm{ml}$ assay).

Comparison of $v W F$ and SFM incorporation in polymerizing fibrin. The incorporation of ${ }^{131} \mathrm{I}-\mathrm{vWF}$ in polymerizing fibrinplatelet thrombi was compared with that of ${ }^{125}$ I-fibrinogen. Table III demonstrates that the extent of incorporation of ${ }^{131} \mathrm{I}-\mathrm{vWF}$ was dependent on the presence of glycoprotein Ib on the platelet surface, since plasmin treatment of FP (26) reduced vWF incorporation in platelet-fibrin thrombi by $50 \%$. In contrast, ${ }^{125} \mathrm{I}$ fibrinogen showed no such dependence, $40 \pm 5 \%$ being converted to fibrin and incorporated in the fibrin-platelet thrombus using normal plasma, vWF-deficient plasma, or plasmin-treated FP. The incorporation of human serum albumin was similarly unaffected by the presence of vWF, with $<1 \%$ being incorporated in the presence or absence of vWF (Table III).
Table III. Extent of Plasma Protein Incorporation in Fibrin Thrombi

\begin{tabular}{ll}
\hline Protein & $\begin{array}{l}\text { Extent } \\
\text { (Fx total protein) }\end{array}$ \\
\hline${ }^{131}$ I-vWF* & \\
Normal plasma + FP & $0.13 \pm 0.01$ \\
Normal plasma + plasmin-treated FP & $0.07 \pm 0.01$ \\
${ }^{125}$ I-fibrinogen $\neq$ & \\
Normal plasma + FP & $0.40 \pm 0.05$ \\
vWF-deficient plasma + FP & $0.40 \pm 0.05$ \\
Normal plasma + plasmin-treated FP & $0.39 \pm 0.04$ \\
${ }^{125}$ I-human serum albumin§ & \\
Normal plasma + FP & $0.0044 \pm 0.0002$ \\
vWF-deficient plasma + FP & $0.0050 \pm 0.0001$ \\
\hline
\end{tabular}

All results are expressed as the mean \pm SEM of two experiments done in duplicate. Plasmas were diluted 1:10 in all experiments.

* $17 \mu \mathrm{g} / \mathrm{ml} \mathrm{vWF}$ was used in these assays.

$\ddagger 280 \mu \mathrm{g} / \mathrm{ml}$ fibrinogen was used in these assays.

$\$ 2 \mathrm{mg} / \mathrm{ml}$ albumin was used in these assays; in order to detect this small amount of incorporated protein, the clot was rinsed three times with TBS and counted directly.

Binding of SFM to $v W F$. In order to demonstrate that SFM binds to vWF, $50 \mu \mathrm{g}$ of vWF was incubated with both ${ }^{125} \mathrm{I}$-fibrinogen and ${ }^{125} \mathrm{I}-\mathrm{SFM}$ for $5 \mathrm{~min}$ in $50 \mu \mathrm{l}$ of TBS, then applied to a Sephacryl S-1000 column. As shown in Fig. 2 , in the presence of vWF, SFM elutes at the void volume, whereas in its absence, SFM elutes well within the column volume at approximately the same volume as fibrinogen. These data indicate that SFM forms a complex with vWF under these experimental conditions.

Binding of glycocalicin to SFM and $v W F$. Further chromatographic experiments were performed to demonstrate the binding of purified glycocalicin to vWF and SFM. ${ }^{125} \mathrm{I}-\mathrm{Glyco}$ calicin was incubated for $5 \mathrm{~min}$ in $50 \mu \mathrm{l}$ of TBS with either vWF,

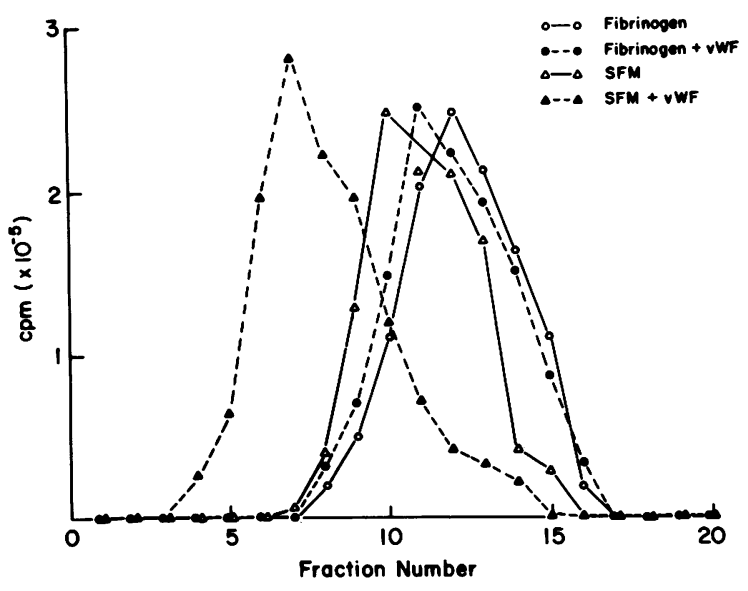

Figure 2. Binding of SFM to vWF. A $50-\mu 1$ sample containing $70 \mu \mathrm{g}$ of ${ }^{125} \mathrm{I}$-fibrinogen $\left(1.5 \times 10^{6} \mathrm{cpm}\right)$ or $70 \mu \mathrm{g}$ of ${ }^{125} \mathrm{I}$-SFM $\left(1.5 \times 10^{6}\right.$ $\mathrm{cpm}$ ) without or with $50 \mu \mathrm{g}$ of $\mathrm{vWF}$ was applied to a $6.0 \times 0.7 \mathrm{~cm}$ column of Sephacryl S-1000 and the column eluted with TBS, $2 \mathrm{mM}$ GPRP, and $48 \mu \mathrm{M}$ PPACK at $25^{\circ} \mathrm{C}$. The radioactivity in each of twenty $200-\mu 1$ fractions was measured. The void volume was determined using ${ }^{125} \mathrm{I}-\mathrm{vWF}$ and found to be $1.2 \mathrm{ml}$ (fraction 6). 
SFM, or vWF and SFM, then applied to a Sephacryl S-1000 column. As shown in Fig. 3, glycocalicin elutes well within the column volume when applied by itself or with vWF or SFM. In the presence of both vWF and SFM (1:1:1 molar ratios), however, glycocalicin elutes at the void volume. These data in conjunction with those of Fig. 2 suggest that glycocalicin forms a ternary complex with SFM and vWF under the conditions of this experimental system.

Binding of $v W F$ to FM-Matrex. In order to quantitate the binding of vWF to fibrin monomer, ${ }^{125} \mathrm{I}-\mathrm{vWF}$ was incubated with FM-Matrex and binding assessed as described in Methods. Fig. 4 demonstrates that binding was specific and saturable, with an approximate apparent $K_{\mathrm{D}}$ of $15 \mu \mathrm{g} / \mathrm{ml}$ (the concentration of $\mathrm{vWF}$ producing half-maximal binding). At saturation, $1.3 \mathrm{vWF}$ molecules (monomers) bound per 1.0 fibrin monomers, assuming $4.1 \times 10^{5} \mathrm{FM}$ coupled per Matrex bead.

Binding of glycocalicin to FM-Matrex and $v W F$. Glycocalicin binding to FM-Matrex was measured in the presence and absence of saturating concentrations of vWF $(20 \mu \mathrm{g} / \mathrm{ml})$. Fig. 5 shows that in the presence of vWF, glycocalicin binding was specific and saturable, as well, with an approximate apparent $K_{\mathrm{D}}$ of 5 $\mu \mathrm{g} / \mathrm{ml}$ (the concentration of glycocalicin producing half-maximal binding). Specific binding only occurred in the presence of vWF and, at saturation, 0.8 molecules of glycocalicin bound per molecule of fibrin monomer, assuming $4.1 \times 10^{5}$ fibrin monomers coupled per Matrex bead.

\section{Discussion}

The data presented here show that platelet incorporation in an evolving fibrin thrombus is dependent on vWF. Under the conditions of our in vitro system, the initial rate of incorporation is markedly reduced in the absence of vWF. The extent of platelet incorporation is also reduced, but less dramatically. Purified vWF restores the initial rate and extent of incorporation.

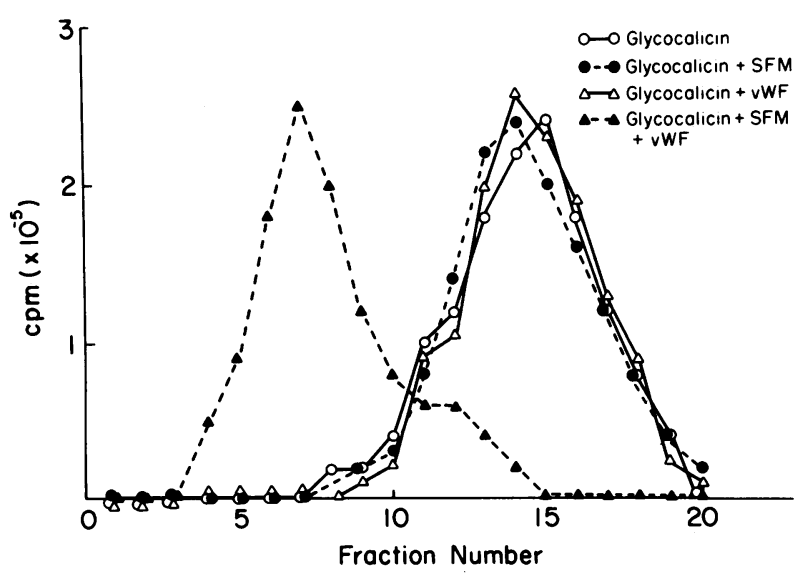

Figure 3. Binding of glycocalicin to SFM and vWF. A 50- $\mu$ l sample containing $30 \mu \mathrm{g}$ of ${ }^{125} \mathrm{I}$-glycocalicin $\left(1.5 \times 10^{6} \mathrm{cpm}\right)$ alone, with $50 \mu \mathrm{g}$ of vWF $(\Delta)$, with $70 \mu \mathrm{g}$ of SFM, or with $50 \mu \mathrm{g}$ of vWF and $70 \mu \mathrm{g}$ of SFM ( $\triangle$ ) was applied to a $6.0 \times 0.7 \mathrm{~cm}$ Sephacryl S-1000 column and the column eluted with TBS, $2 \mathrm{mM}$ GPRP, and $48 \mu \mathrm{M}$ PPACK at $25^{\circ} \mathrm{C}$. The radioactivity in each of twenty $200-\mu l$ fractions was measured. The void volume was determined using ${ }^{125} \mathrm{I}-\mathrm{vWF}$ and found to be $1.2 \mathrm{ml}$ (fraction 6) and the column volume was determined using ${ }^{125} \mathrm{I}-\mathrm{Na}$ and found to be $7.2 \mathrm{ml}$ (fraction 16 ).

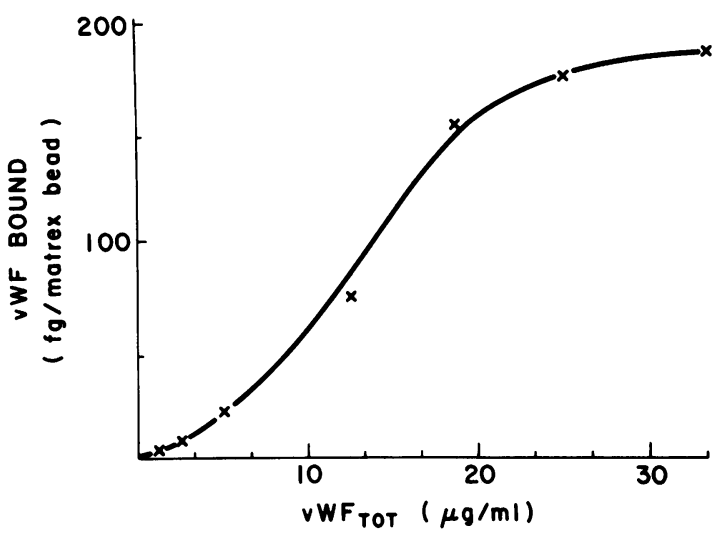

Figure 4. Specific binding of vWF to FM-Matrex. $3.2 \times 10^{6}$ Matrex beads with $4.1 \times 10^{5}$ molecules of fibrin monomer/bead were incubated with $0.4 \mathrm{ml}$ of TBS with stirring at $900 \mathrm{rpm}$ at $25^{\circ} \mathrm{C}$ for $1 \mathrm{~h}$ with increasing concentrations of ${ }^{125} \mathrm{I}-\mathrm{vWF}$. At the end of the incubation period, $0.1 \mathrm{ml}$ was centrifuged through $0.2 \mathrm{ml}$ of $20 \%$ sucrose in TBS at $8,700 \mathrm{~g}$ for $2.5 \mathrm{~min}$ and FM-Matrex-bound vWF measured. Nonspecific binding was determined by measuring the amount of ${ }^{125} \mathrm{I}$ vWF bound in the presence of a 20 -fold excess of unlabeled vWF. Each point represents the average of three experiments done in duplicate.

Niewiarowski and colleagues $(48,49)$ have previously shown that while erythrocytes are incorporated in polymerizing fibrin purely by nonspecific entrapment, platelets are incorporated both by entrapment and by specific binding to some intermediate species generated during the conversion of fibrinogen to fibrin. Our data suggest that this specific binding is mediated by vWF and, furthermore, that vWF accomplishes this by binding both to a receptor site on glycoprotein Ib and to fibrin monomer.

The attenuation of platelet incorporation by a polyclonal anti-vWF antibody and by vWF-deficient plasma, as well as its

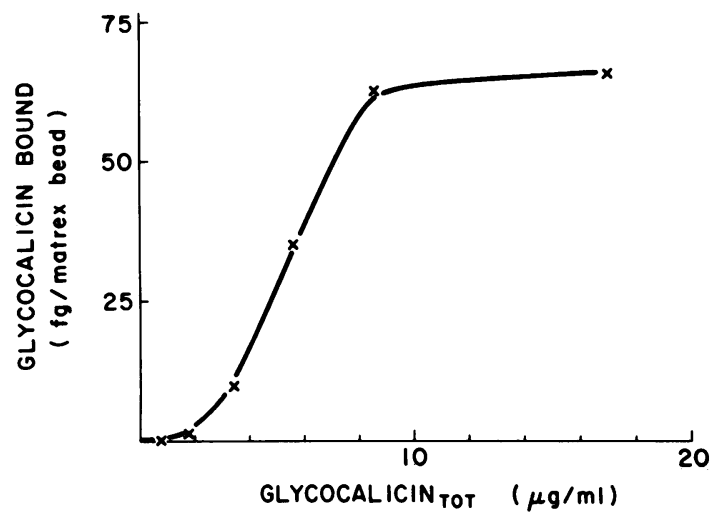

Figure 5. Specific binding of glycocalicin to FM-Matrex in the presence of vWF. $2.4 \times 10^{6}$ Matrex beads with $4.1 \times 10^{5}$ molecules of $f-$ brin monomer/bead were incubated with $0.3 \mathrm{ml}$ of TBS with stirring at $900 \mathrm{rpm}$ at $25^{\circ}$ for $1 \mathrm{~h}$ with increasing concentrations of ${ }^{125} \mathrm{I}$-glycocalicin in the presence of $20 \mu \mathrm{g} / \mathrm{ml} \mathrm{vWF}$. At the end of the incubation period, $0.1 \mathrm{ml}$ was centrifuged through $0.2 \mathrm{ml}$ of $20 \%$ sucrose in TBS at $8,700 \mathrm{~g}$ for $2.5 \mathrm{~min}$ and FM-Matrex-bound glycocalicin measured. Nonspecific binding was determined by measuring the amount of ${ }^{125} \mathrm{I}$ glycocalicin bound in the presence of a 20-fold excess of unlabeled glycocalicin. Each point represents the average of two experiments done in triplicate. 
restoration by addition of purified vWF, supports the role of vWF in this process. Formalin-fixation, under conditions that preserve glycoprotein Ib availability and affinity for vWF but impair glycoprotein IIb/IIIa function, does not inhibit the vWFdependent incorporation of platelets in evolving fibrin thrombi. In contrast, the observation that plasmin treatment of platelets, a process that cleaves glycoprotein $\mathrm{Ib}$ from the platelet surface $(26,50)$, as well as incubation with a monoclonal anti-glycoprotein Ib antibody, markedly impair the vWF-dependent incorporation of platelets in evolving fibrin thrombi support the role of glycoprotein Ib as the vWF-receptor on the platelet surface in this system.

These experiments also demonstrate that vWF can bind to glycoprotein $\mathrm{Ib}$ in the absence of ristocetin. Although it is clear that the glycoprotein Ib-vWF-collagen interaction is critical for platelet adhesion in flowing blood, the physiologic mechanism that regulates vWF binding to glycoprotein Ib had not been defined prior to this study. Thrombin and ADP can initiate binding of both vWF and fibrinogen to glycoprotein IIb/IIIa, but, to date, the only agents found to facilitate vWF binding to glycoprotein $\mathrm{Ib}$ have been cationic polypeptides, such as ristocetin and poly-L-lysine (51). The data presented here with purified proteins show that vWF binds to SFM and that only this binary complex can, in turn, bind to glycocalicin. Using fibrin monomer immobilized on Matrex beads, vWF was found to bind specifically and saturably with an approximate apparent $K_{\mathrm{D}}$ of $15 \mu \mathrm{g} /$ $\mathrm{ml}$. Glycocalicin bound to fibrin monomer immobilized on Matrex beads, as well, but only in the presence of vWF, suggesting that the binding of vWF to fibrin monomer supports glycocalicin binding either by producing a binding site comprised of fibrin and VWF epitopes or as a result of a conformational change in vWF or fibrin monomer induced by binding. The stoichiometry of binding is 1:1.3:0.8 fibrin monomer/vWF/glycocalicin. That greater than one molecule (monomer) of vWF binds per complex suggests the possibility that a dimer of VWF is the important for the production of the ternary complex, but further studies are needed to clarify this possibility. These observations thus strongly suggest that SFM functions as a "ristocetin-equivalent" which, on binding to vWF, facilitates its binding to glycoprotein Ib.

There is other evidence to support the role of $\mathrm{vWF}$, polymerizing fibrin, and platelets in thrombus generation. In addition to the suggestion by Niewiarowski and colleagues $(48,49)$ that platelets are incorporated into polymerizing fibrin by specific receptor-mediated binding as well as entrapment, Turitto and associates (29) have demonstrated recently that at intermediate shear rates $\left(\sim 650-1,300 \mathrm{~s}^{-1}\right)$ platelet adhesion to subendothelium in vWF-deficient plasma is normal, but thrombus dimensions are significantly reduced compared with both normal controls and hemophiliacs. In addition, they report that the deposition of fibrin is essentially normal in this VWF-deficient plasma. Weiss and Rogers (52) showed that two patients with congenital afibrinogenemia had diminished platelet aggregation in response to ADP and epinephrine, and a prolonged bleeding time. This latter phenomenon could be explained by abnormal platelet aggregation, as well as abnormal platelet adhesion due to impaired production of SFM essential for platelet recruitment in the evolving platelet-fibrin thrombus.

The potential relevance of the observations first made in experiments with FP was confirmed by experiments using fresh platelets and $B$. atrox venom to produce fibrin. $B$. atrox venom does not affect the platelet surface nor induce platelet aggregation or the release reaction $(53,54)$ as thrombin does, but acts solely to convert fibrinogen to fibrin. While the low concentration of fibrinogen used in these experiments may be considered physiologically inappropriate, this concentration was chosen to slow the rate of fibrin polymerization sufficiently so that the differences in initial rate of incorporation of platelets could be readily discerned. When higher concentrations of plasma were used, the effect on initial rate was less marked, but the effect on extent of incorporation persisted (Table I). The actual physiologic relevance of these observations is difficult to determine with certainty since local concentrations of all of the components-vWF, SFM, and glycocalicin/glycoprotein Ib-may vary greatly at sites of injury compared with their concentrations in normal plasma. Thus, the overall importance of the mechanism described here to hemostasis will have to await further experimentation in increasingly complex artificial systems.

The results of a study by Hantgan and colleagues (55) suggest that platelet activation is a prerequisite for binding to fibrin and that unactivated platelets only bind to polymerizing fibrin in a nonspecific manner through pure entrapment. This latter conclusion contradicts both our data and the data presented in many earlier studies $(27,28,48,49,56)$ that both nonspecific entrapment and specific binding interactions between unactivated platelets and polymerizing fibrin promote platelet incorporation in evolving fibrin thrombus. The reasons for this difference between the work of Hantgan and colleagues and the present data may represent differences in experimental conditions. For example, Hantgan's group did not stir the suspension of platelets and polymerizing fibrin, while we and other experimenters $(27$, $28,48,49,56$ ) did; in addition, the fibrinogen used in Hantgan's experiments was labeled with the bulky, aromatic fluorophore, dansylcadaverine, the effect of which on protein-protein interactions in this complex system is not clear. In any case, the fact that activated platelets are known to bind fibrinogen (57-59) argues that activated platelets could, indeed, provide more binding sites than unactivated platelets for interaction with polymerizing fibrin, perhaps through glycoprotein IIb/IIIa in addition to glycoprotein $\mathrm{Ib}$, thereby potentiating the extent of incorporation in evolving platelet-fibrin thrombus. Thus, in one sense, the data of Hantgan and colleagues (55) are not as much contradictory as complementary to the data presented here.

These data clearly demonstrate that vWF is incorporated into polymerizing fibrin by binding to SFM and that this binding facilitates binding of $\mathrm{VWF}$ to glycoprotein Ib. This incorporation of vWF in fibrin thrombus may enhance the number of platelets included in the thrombus and may augment further fibrin production by delivering Factor VIII $_{c}$ to the activated coagulation cascade.

\section{Acknowledgments}

The authors wish to thank Jane Freedman and Jan Kim for excellent technical assistance.

This work was supported by National Institutes of Health grants HL17513-10 and HL-35014-01. J.L. is the recipient of a Clinician-Scientist Award from the American Heart Association.

\section{References}

1. Baumgartner, H. R. 1977. Platelet interaction with collagen fibrils in flowing blood. I. Reaction of human platelets with alpha-chymotrypsindigested subendothelium. Thromb. Haemostasis. 37:1-16. 
2. Baumgartner, H. R., T. B. Tschopp, and H. J. Weiss. 1977. Platelet interaction with collagen fibrils in flowing blood. II. Impaired adhesion and aggregation in bleeding disorders. Thromb. Haemostasis. 37:17-28.

3. Legrand, Y. J., A. Rodriguez-Zeballos, G. Kartalis, F. Fauvel, and J. P. Caen. 1978. Adsorption of factor VIII-antigen-activity complex by collagen. Thromb. Res. 13:909-911.

4. Santoro, S. A. 1981. Adsorption of von Willebrand factor/factor VIII by the genetically distinct interstitial collagens. Thromb. Res. 21: 689-693.

5. Booyse, F. M., S. Feder, and A. J. Quarfoot. 1982. Culture-produced subendothelium. II. Effect of plasma, F.VIII R:VWF and fibronectin on interaction of normal platelets with normal and von Willebrand porcine aortic subendothelium. Thromb. Res. 28:299-311.

6. Leytin, V. L., N. A. Gorbunova, F. Misselwitz, I. D. Novikov, E. A. Podrez, O. P. Plyusch, E. A. Likhachova, V. S. Repin, and V. N. Smirnov. 1984. Step-by-step analysis of adhesion of human platelets to a collagen-coated surface. Defect in initial attachment and spreading of platelets in von Willebrand's disease. Thromb. Res. 34:51-63.

7. Houdijk, W. P. M., K. S. Sakariassen, P. F. E. M. Nievelstein, and J. J. Sixma. 1985. Role of Factor VIII-von Willebrand factor and fibronectin in the interaction of platelets in flowing blood with monomeric and fibrillar human collagen types I and III. J. Clin. Invest. 75:531-540.

8. Weiss, H. J., T. B. Tschopp, H. R. Baumgartner, I. I. Sussman, M. M. Johnson, and J. J. Egan. 1974. Decreased adhesion of giant (Bernard-Soulier) platelets to subendothelium. Further implications on the role of von Willebrand factor in hemostasis. Am. J. Med. 57:920-925.

9. Solum, N. O., I. Hagen, M. Petersten, and T. Gjemdal. 1979. Absence of the 145,000 molecular weight, soluble membrane glycoprotein: lack of agglutination. Thromb. Haemostas. 42:1626-1629.

10. Coller, B. S., E. I. Peerschke, L. E. Scudder, and C. A. Sullium. 1983. Studies with a murine monoclonal antibody that abolishes ristocetin-induced binding of von Willebrand factor to platelets: additional evidence in support of GpIb as a platelet receptor for von Willebrand factor. Blood. 61:99-110.

11. Fujimoto, T., and J. Hawiger. 1982. Adenosine diphosphate induces binding of von Willebrand factor to human platelets. Nature (Lond.). 297:154-156.

12. Fujimoto, T., S. O'Hara, and J. Hawiger. 1982. Thrombin-induced exposure and prostacyclin inhibition of the receptor of Factor VIII/von Willebrand factor in human platelets. J. Clin. Invest. 69:1212-1222.

13. Ruggeri, Z. M., L. DeMarco, L. Gatti, R. Bader, and R. R. Montgomery. 1983. Platelets have more than one binding site for von Willebrand factor. J. Clin. Invest. 72:1-12.

14. Gralnick, H. R., S. B. Williams, and B. S. Coller. 1984. Fibrinogen competes with von Willebrand factor for binding to the glycoprotein IIb/IIIa complex when platelets are stimulated with thrombin. Blood. 64:797-800.

15. Tschopp, T. B., H. J. Weiss, and H. R. Baumgartner. 1974. Decreased adhesion of platelets to subendothelium in von Willebrand's disease. J. Lab. Clin. Med. 83:296-300.

16. Weiss, H. J., H. R. Baumgartner, T. B. Tschopp, V. T. Turitto, and D. Cohen. 1978. Correction by Factor VIII of the impaired platelet adhesion to subendothelium in von Willebrand's disease. Blood. 51:267279.

17. Sakariassen, K. S., P. A. Bolhuis, and J. J. Sixma. 1979. Human blood platelet adhesion to artery subendothelium is mediated by factor VIII-von Willebrand factor bound to the subendothelium. Nature (Lond.). 279:635-638.

18. Schullek, J., J. Jordan, and R. R. Montgomery. 1984. Interaction of von Willebrand factor with human platelets in the plasma milieu. $J$. Clin. Invest. 73:421-428.

19. Marcus, A. J., D. Zucker-Franklin, L. B. Safier, and H. L. Ullman. 1966. Studies on human platelet granules and membranes. J. Clin. Invest. 45:14-28.

20. Schick, P. K. 1979. The role of platelet membrane lipids in platelet hemostatic activities. Semin. Hematol. 16:221-233.

21. Marcus, A. J. 1978. The role of lipids in platelet function-with particular reference to the arachiconic acid pathway. J. Lipid Res. 19: 793-826.

22. Giddings, J. C., S. A. M. Shearn, and A. L. Bloom. 1978. Plateletassociated coagulation factors: immunologic detection and the effects of calcium. Br. J. Haematol. 39:569-577.

23. Day, H. J., and N. O. Solum. 1973. Fibrinogen associated with subcellular platelet particles. Scand. J. Haematol. 10:136-143.

24. Slot, J. W., B. N. Bouma, R. Montgomery, and T. S. Zimmerman. 1978. Platelet factor VIII-related antigen: immunofluorescent localization. Thromb. Res. 13:871-881.

25. Zucker, M. B., M. J. Broekman, and K. L. Kaplan. 1979. Factor VIII-related antigen in human blood platelets: localization and release by thrombin and collagen. J. Lab. Clin. Med. 94:675-682.

26. Adelman, B., A. D. Michelson, J. Loscalzo, J. Greenberg, and R. I. Handin. 1985. Plasmin effect on platelet glycoprotein Ib-von Willebrand factor interactions. Blood. 65:32-40.

27. Hovig. T., L. Jorgenson, M. A. Packham, and J. F. Mustard. 1968. Platelet adhesion to fibrin and collagen. J. Lab. Clin. Med. 71: $29-40$.

28. Niewiarowski, S., E. Regoeczi, G. J. Steward, A. F. Senyi, and J. F. Mustard. 1972. Platelet interaction with polymerizing fibrin. $J$. Clin. Invest. 51:685-700.

29. Turitto, V. T., H. J. Weiss, and H. R. Baumgartner. 1984. Platelet interaction with rabbit subendothelium in von Willebrand's disease: altered thrombus formation distinct from defective platelet adhesion. $J$. Clin. Invest. 74:1730-1741.

30. Allain, J. P., J. A. Cooper, R. H. Wagner, and K. Brinkhous. 1975. Platelets fixed with paraformaldehyde: a new reagent for assay of von Willebrand factor and platelet aggregation. J. Lab. Clin. Med. 85: 318-328.

31. Brinkhous, K. M., and M. S. Read. 1978. Preservation of platelet receptors for platelet aggregating/von Willebrand factor by air drying, freezing, or lyophilization. Thromb. Res. 13:595-597.

32. Born, G. V. R., and M. J. Cross. 1963. The aggregation of blood platelets. J. Physiol. 168:178-195.

33. Loscalzo, J., and R. I. Handin. 1984. Conformational domains and structural transitions of human von Willebrand protein. Biochemistry. 23:3880-3886.

34. Howard, M. A., and B. G. Firkin. 1971. Ristocetin: a new tool in the investigation of platelet aggregation. Thromb. Diath. Haemorrh. 26:326-329.

35. Olson, J. D., W. J. Brockway, D. N. Fass, M. A. Magnusson, and E. J. W. Bowie. 1975. Evaluation of ristocetin-von Willebrand factor assay and ristocetin-induced platelet aggregation. Am. J. Clin. Pathol. 63:210-218.

36. Ruggeri, Z. M., and T. S. Zimmerman. 1980. Variant von Willebrand's disease. Characterization of two subtypes by analysis of multerimeric composition of Factor VIII/von Willebrand factor in plasma and platelets. J. Clin. Invest. 65:1318-1322.

37. Ruggeri, Z. M., and T. S. Zimmerman. 1981. The complex multimeric composition of Factor VIII/von Willebrand factor. Blood. 57: $1140-1143$.

38. Slayter, H. S., J. Loscalzo, P. Bockenstedt, and R. I. Handin. 1985. Native conformation of human von Willebrand protein. Analysis by electron microscopy and quasi-elastic light scattering. J. Biol. Chem. 260:8559-8563.

39. Loscalzo, J., H. S. Slayter, and R. I. Handin. 1986. Subunit structure and assembly of von Willebrand factor polymer. Complementary analysis by electron microscopy and quasielastic light scattering. Biophys. J. 49:49-50.

40. Michelson, A. D., J. Loscalzo, B. Melnick, B. S. Coller, and R. I. Handin. 1986. Partial characterization of a binding site for von Willebrand's factor on glycocalicin. Blood. 67:19-26.

41. Phillips, D. R. 1972. Effect of trypsin on the exposed polypeptides and glycoproteins in the human platelet membrane. Biochemistry. 11: 4582-4588.

42. Nachman, R. L., A. Hubbard, and B. Ferris. 1973. Iodination of human platelet membranes. J. Biol. Chem. 248:2928-2936. 
43. Laudano, A. P., and R. F. Doolittle. 1980. Studies on synthetic peptides that bind to fibrinogen and prevent fibrin polymerization: structural requirements, number of binding sites, and species differences. Biochemistry. 19:1013-1019.

44. Kettner, C., and E. Shaw. 1979. D-Phe-Pro-ArgCH ${ }_{2}$ : A selective affinity label for thrombin. Thromb. Res. 14:969-973.

45. Latallo, Z., A. P. Fletcher, N. Alkjaersig, and S. Sherry. 1962. Influence of $\mathrm{pH}$, ionic strength, neutral ions, and thrombin on fibrin polymerization. Am. J. Physiol. 202:675-680.

46. Coller, B. S. 1980. Interaction of normal, thrombasthenic, and Bernard-Soulier platelets with immobilized fibrinogen. Defective plateletfibrinogen interaction in thrombasthenia. Blood. 55:169-178.

47. Lowry, O. H., N. J. Rosebrough, A. L. Farr, and R. Randall. 1951. Protein measurement with the Folin phenol reagent. J. Biol. Chem. 193:265-275.

48. Niewiarowski, S., and G. J. Stewart. 1978. Interaction of blood cells with fibrinogen and polymerizing fibrin. In Platelets: A Multi-disciplinary Approach. G. DeGaetano and S. Garattini, editors. Raven Press, New York.

49. Brown, R. S., S. Niewiarowski, G. J. Stewart, and M. Millman. 1977. A double-isotope study of incorporation of red cells and platelets into fibrin. J. Lab. Clin. Med. 90:130-140.

50. Schafer, A. I., and B. Adelman. 1985. Plasmin inhibition of platelet function and of arachidonic acid metabolism. J. Clin. Invest. 75:456461.

51. Rosborough, T. K. 1980. Von Willebrand factor, polycations, and platelet agglutination. Thromb. Res. 17:481-490.
52. Weiss, H. J., and J. Rogers. 1971. Fibrinogen and platelets in the primary arrest of bleeding: studies in two patients with congenital afibrinogenemia. N. Engl. J. Med. 285:369-374.

53. Niewiarowski, S., G. J. Stewart, and A. Nath. 1975. ADP, thrombin, and Bothrops atrox thrombin-like enzyme in platelet-dependent fibrin retraction. Am. J. Physiol. 229:737-745.

54. Tangen, O., O. K. Wik, and H. J. Berman. 1973. The effect of thrombin, reptilase, and fibrinopeptide B-releasing enzyme from the venom of the southern copperhead snake on rabbit platelets. Microvasc. Res. 6:342-346.

55. Hantgan, R. R., R. G. Taylor, and J. C. Lewis. 1985. Platelets interact with fibrin only after activation. Blood. 65:1299-1311.

56. Brosstad, F., M. Rygh, P. Kierulf, H. C. Godal, and C. Eika. 1980. Interaction of platelets with soluble, polymerizing and polyermized Des-AA and Des-AABB fibrin in human plasma. Thromb. Res. 18:123130.

57. Mustard, J. F., M. A. Packham, R. L. Kinlough-Rathbone, D. W. Perry, and E. Regoeczi. 1978. Fibrinogen and ADP-induced platelet aggregation. Blood. 52:453-466.

58. Marguerie, G. A., T. S. Edgington, and E. F. Plow. 1980. Interaction of fibrinogen with its platelet receptor as part of a multistep reaction in ADP-induced platelet aggregation. J. Biol. Chem. 255:154-161.

59. Marguerie, B. A., N. Thomas-Maison, M.-J. Larrieu, and E. F. Plow. 1982. The interaction of fibrinogen with human platelets in a plasma milieu. Blood. 59:91-95. 